\title{
Climate change adaptation in agriculture: A computable general equilibrium analysis of land-use change in Nepal
}

\begin{abstract}
This paper investigates the feasibility of changes in cropland-use as an adaptation strategy to minimise the economy-wide costs of climate change on agriculture. Nepal makes an interesting case study as it is one of the most vulnerable agricultural economies within South Asia. We develop a comparative static multi-household computable general equilibrium (CGE) model for Nepal, with a nested set of constant elasticity of transformation (CET) functional forms, to model the allocation of land within different agricultural sectors. Land transformation elasticities in these CET functions are allowed to reflect the ease of switching from one crop to another based on their agronomic characteristics. The results suggest that, in the long run, farmers in Nepal tend to allocate land to crops that are comparatively less impacted by climate change, such as paddy, thereby minimising the economy-wide impacts of climate change. Furthermore, the results reveal that land-use change tends to reduce the income disparity between different household groups by significantly moderating the income losses of marginal farmers. Therefore, it is suggested that policy makers in Nepal should prioritise schemes such as providing climatesmart paddy varieties (i.e., those that are resistant to heat, drought and floods) to farmers, subsidising fertilizers, improving agronomic practices, and educating farmers to switch from crops that are highly impacted by climate change to those that are not, such as paddy.
\end{abstract}

JEL Classification: Q54, Q15, I32, C68

Keywords: Climate change; general equilibrium; land-use change; Nepalese agriculture

\section{Introduction}

A considerably growing body of literature on climate change has a common understanding on two major issues. First, given the importance of agriculture to employment and people's livelihoods in developing countries such as Nepal, the loss of agricultural productivity due to climate change is of great social and economic concern. Many socio-economic sectors besides agricultural value chains are also likely to experience indirect effects of discrepancies in income and consumption. As a consequence of these threats, climate change imposes additional stresses to the social and economic challenges that the poorest already face (IPCC, 2013), highlighting 
and accelerating their vulnerabilities, as their livelihoods depend on already overstrained climatesensitive resources and their social welfare systems are weak. By directly depleting the agricultural resources that poor people depend on for their livelihoods, climate change increases their chances of falling into a cycle of poverty from which it is difficult to escape. In this situation, even optimal success in global action towards mitigating climate change will be insufficient to build resilience and compensate for the damage cost (IPCC, 2013; Nelson \& Shively, 2014). An effective framework of potential adaptations is essential to eradicate the escalating poverty in developing countries (Arndt, Robinson, \& Willenbockel, 2011; UNFCCC, 2015). In the absence of such a consolidated framework of adaptation options, it is likely that farmers will implement comparatively less-beneficial practices in the long term.

Second, it is important to implement locally led adaptations to climate change in agriculture, particularly when smallholders have inadequate access to official strategies. In this sense, farmers' practices, which are based on their ad-hoc experiences, such as changing crop patterns, improving grazing patterns, cultivating heat-resistant crops, using better fertilizers, and using rain-water harvesting for irrigation, can help to reduce the impacts of climate change. However, it is unknown what the maximum benefit smallholders in developing countries can enjoy from such adaptations (Claessens et al., 2012; Esham \& Garforth, 2013).

Gradually changing the pattern of land-use from high-impact crops to low-impact ones is one of the best adaptation options that farmers in Nepal have been experimenting with to minimize the impacts of climate change. As climate-induced impacts are highly variable among crops and croplands due to different agronomic conditions, farmers tend to supply more land to lessimpacted crops in order to maximize their yields. Changing land-use is crucial not only for food security and the overall economic growth of the agricultural sector but also for helping the poorest people in developing countries to escape the cycle of poverty. However, significant challenges facing the farmers in developing countries are to understand the actual agronomic feasibility of switching crops and to experiment with land-use change practices that maximise farm revenue as well as food security. In this sense, a study on assessing the impacts of climate change and the benefits of the land-use change is important in the current literature.

Although there is clear evidence that agricultural systems in developing countries are highly vulnerable to climate change, there have been relatively few detailed studies carried out to examine the potential of climate-change adaptations on agriculture. Some partial equilibrium studies (e.g., Kumar, 2011; Mendelsohn, 2007; Saito, 2012; Seo, Mendelsohn, Dinar, Hassan, \& Kurukulasuriya, 2009) have attempted to assess the impacts of climate change and possible climate-change adaptations on agriculture at national and global levels. However, these studies 
have three major limitations. First, their results are skewed towards individual perceptions and practices, and the uncertainty and long timeframes allied with climate change limit the findings. Second, most of these studies emphasize crop production as one of the major characteristics of partial equilibrium analysis (as mentioned in Elbehri \& Burfisher, 2015), and disregard direct and indirect linkages with the overall economy. Third, none of these studies has investigated climatechange adaptations in relation to differences between households.

A few studies consider the economy-wide impacts of climate change on agriculture. In an economy-wide approach, top-down computable general equilibrium (CGE) modelling is generally used (e.g., Bandara \& Cai, 2014; Bezabih, Chambwera, \& Stage, 2011; Eboli, Parrado, \& Roson, 2010; Robinson et al., 2014) for assessing the economic effects of climate change and evaluating the efficacy of climate policies. These studies have found that unfavourable climate change in several developing countries is not only likely to induce discrepancies in income and consumption but also bring about a huge decline in their overall economic performance.

Among the specification parameters affecting the quantitative and qualitative results of these CGE models, substitution and transformation elasticity of primary factors for various uses have a major influence (Palatnik et al., 2011). Several CGE models have used functions such as constant elasticity of substitution (CES) and constant elasticity of transformation (CET) for this purpose. The original ORANI-G model (Dixon, Parmenter, Sutton, \& Vincent, 1982) also uses a CES function as a factor composite for production, assuming a significant elastic CES sub-set for labour among several occupational skill groups. Such models assume that land is fixed for an industry, which we argue is extremely likely to result in over- or under- estimation of climatechange impacts due to the exclusion of land-transformation possibilities among crops. In developing countries, individual farmers and households operating at the micro-level make most of the land-use decisions to adapt to the threats of climate change. Therefore, in this paper, we attempt to model and assess individual decisions regarding land-use change among different industries in a more mathematical way.

We propose a simple model, based on the Nepalese economy that provides a general framework for allowing climate-change impacts and adaptation strategies to be tested. In contrast to the existing comparative-static CGE assessments of climate-change impacts on agriculture production (e.g., Arndt, Strzepeck, et al., 2011; Bosello \& Zhang, 2005; Hertel, Rose, Tol, Taylor, \& Francis, 2009), the approach presented here is able to capture the possible landuse change for several crops.

Although recent studies (e.g., Fujimori, Hasegawa, Masui, \& Takahashi, 2014; Hertel, Burke, \& Lobell, 2010; Li, Taheripour, Preckel, \& Tyner, 2012; Palatnik et al., 2011) have used CET in 
land substitution systems, the results have some serious limitations. First, the results are limited to a few agricultural sectors where, we argue, there is an extreme chance of an individual sector controlling the model parameters. Second, these studies have not tested the possibility of crop switching with a range of CET values. This has created a serious gap in the policy recommendations, in which the implication of such beneficial land-use to local farmers is missing.

Therefore, the main objective of this paper is to modify the widely used assumption of "fixed land supply for a given industry", by allowing farmers to supply land to crops that are less affected by climate change, subject to any agronomic constraints; and to examine the economywide impacts of climate change-induced agricultural loss both "with" and "without" land-use change. The rest of the paper is organized as follows: Section 2 justifies the rationale of selecting Nepal as a case study, including a literature survey on climate-change impacts on Nepalese agriculture; Section 3 illustrates the methodology, including the empirical model and framework; Section 4 depicts the simulation results; and Section 5 offers some short policy discussion and conclusions.

\section{Motivation and background of the study}

We have purposefully chosen Nepalese agriculture to illustrate the economy-wide impacts of changing land-use pattern as adaptation strategy to climate change for a number of reasons. First, the agricultural sector plays a vital role in the economy of Nepal, particularly in the rural sector. Around $80 \%$ of Nepalese households are located in rural farms or regional areas, but only $50 \%$ of their income is generated from agricultural sources (World Bank, 2012), which is insufficient to provide a secure livelihood. Although the contribution of agriculture to the national GDP has been decreasing during recent years-from more than 50\% in 1995 to about 35\% in 2011/12 (CBS, 2014)-it is still one of the highest among South Asian countries. The agrarian societies in Nepal, who live primarily in rural areas, have the strongest bond with the ecosystems that are sensitive to climate changes. Besides agriculture, the livelihood of the rural population is closely linked to the forest, another climate-sensitive sector. More than $86 \%$ of the energy needs of the population are met by firewood, agricultural residue and animal wastes (CBS, 2014).

Second, due to the country's steep rugged topography, Nepalese agriculture is one of the most vulnerable sectors to climate change in South Asia (Bandara \& Cai, 2014; Chalise, Maraseni, \& Maroulis, 2015). Limited arable lands, a rain-fed farming system and fragile land constructs result in frequent natural disasters. With regard to the climate-change parameters in Nepal, the regional climate-model projections show temperature increases of $1.6^{\circ} \mathrm{C}-2.0^{\circ} \mathrm{C}$ by 
$2030,2.3^{\circ} \mathrm{C}-2.9^{\circ} \mathrm{C}$ by 2050 , and $3.4^{\circ} \mathrm{C}-5.0^{\circ} \mathrm{C}$ by 2080 (Ahmed \& Suphachalasai, 2014). These increases in temperature are likely to result in erratic precipitation, greater soil erosion and droughts in the future. Moreover, prolonged droughts could result in rapid evaporation and ultimately the drying of important water bodies in the mid-eastern parts of Nepal (Gurung \& Bhandari, 2009), which would cause extreme starvation among the poor.

Third, Nepal has relatively low per capita income of USD 562 (CBS, 2014) and, therefore, has been categorised as a least-developed country by the World Bank and other international organisations. Nearly $25 \%$ of the population in Nepal live below the poverty line based on the well-known USD 1.25 per day poverty measurement. Hence, any adverse impacts on Nepalese agriculture as a result of climate change could be disastrous for those living below the poverty line, subsistence farmers in particular, as well as for the national economy in general. Consequently, Nepalese farmers are more vulnerable to climate-change impacts than farmers in more progressive countries, since they already have insufficient resources to confront the many evolving climate-change challenges.

As the agricultural sector in Nepal primarily depends on seasonal rainfall patterns (the system of rain-fed farming dominates, at around $85 \%$ ), precipitation is a major factor that influences crop yields. The annual monsoon provides around 80\% of the year's rainfall (CBS, 2014; Chalise et al., 2015). Although mean annual precipitation varies within the country and no definite trend in aggregate precipitation has been found, there is evidence of extreme precipitation in Nepal. For example, in 2006, the mid-western lowlands (Terai) experienced heavy rains with flash floods, which damaged standing crops and reduced production by 30\% (Pokhrel \& Thapa, 2007). At the same time, the eastern part of Nepal faced an extreme drought, which led to a decrease in rice production by $30 \%$ and a reduced crop production of $12.5 \%$ on a national basis (Malla, 2008). As a late or erratic monsoon quickly turns into crop damages and subsequent food insecurity, climate change influences large and small-scale farming systems and brings about significant changes in crop-growing seasons, crop-growth cycles and cropping patterns.

Table 1 summarises a comprehensive literature survey on climate-change impacts on Nepalese agriculture. According to Joshi, maharjan, and Piya (2011), a time series regression analysis of 1977-2008 shows a positive impact of climate variability, with increases in rice, wheat and maize of $1.7 \%, 2.32 \%$ and $1.49 \%$ respectively. However, a future projection on the basis of these results is not meaningful as climate change has non-linear impacts on crops, and technological advancement which is not included in the model, could have sole impacts in this case. Cline (2007) has reviewed the different approaches of various assessments, and estimated the impacts of climate change on agricultural products globally by 2080 ; overall agricultural 
productivity in Nepal is estimated to decline by $17.3 \%$ if no adaptation or carbon fertilization strategies are implemented and the rate of current technological growth continues.

Similarly, Knox, Hess, Daccache, and Perez Ortola (2011), on the basis of their literature survey, have projected an average change in agricultural productivity in Africa and Asia, which is almost consistent with Hertel et al. (2010) and Bandara and Cai (2014). Hertel et al. (2010) have provided a range of productivity change for all the countries in the world. Some India-based studies $^{1}$ (e.g., Auffhammer, Ramanathan, \& Vincent, 2012; Byjesh, Kumar, \& Aggarwal, 2010; Kumar, 2011; Kumar \& Parikh, 2001) have predicted a range of significant productivity loss in Indian agriculture. Overall, some literature expects notably positive impacts of climate change in certain crops. For example, rice yields are expected to increase till 2030, and some assessments (e.g., Iglesias \& Rosensweig, 2010; Thapa \& Joshi, 2011) have projected a positive impact of climate change on rice and wheat until 2080. Despite the variations in estimates of productivity losses due to climate change in Nepalese agriculture, an average of these estimations can be used as inputs for our modelling analysis, as described in the next section.

\section{Table 1}

Comprehensive literature survey on climate-change impacts in Nepalese agriculture

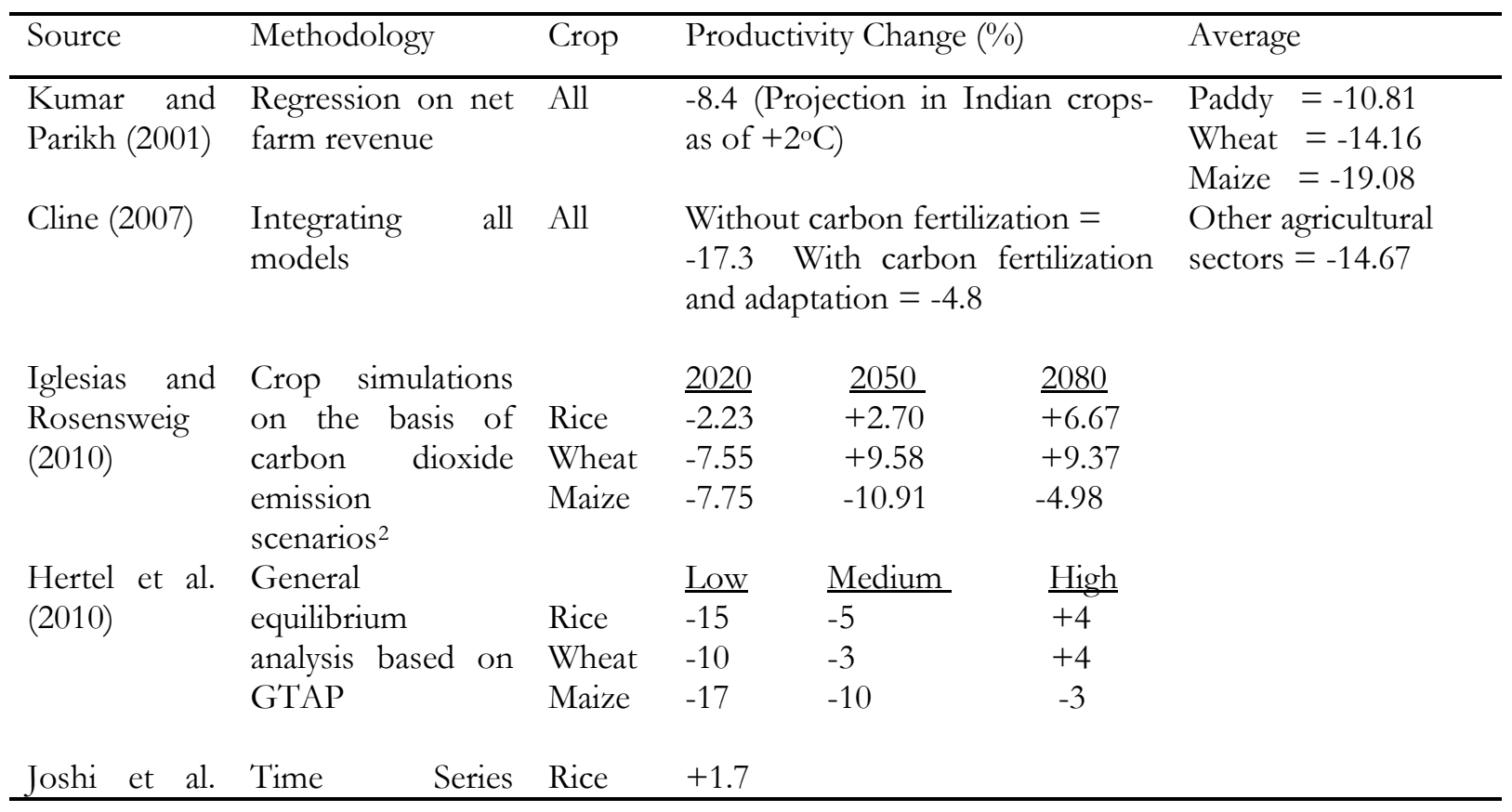

1 A few studies on Indian agriculture are reviewed in this paper, as they have revealed that Indian agriculture is similar to Nepalese farming in many respects (e.g., rain-fed agricultural system, level of technological advancement, and cropping-weather pattern).

2 The data are available for different $\mathrm{CO}_{2}$ emission scenarios of SRES (IPCC, 2000). The set of scenarios consists of six groups drawn from four families: one group each in A2, B1, and B2, and three groups within the A1 family. The A2 scenario is employed for this study. 


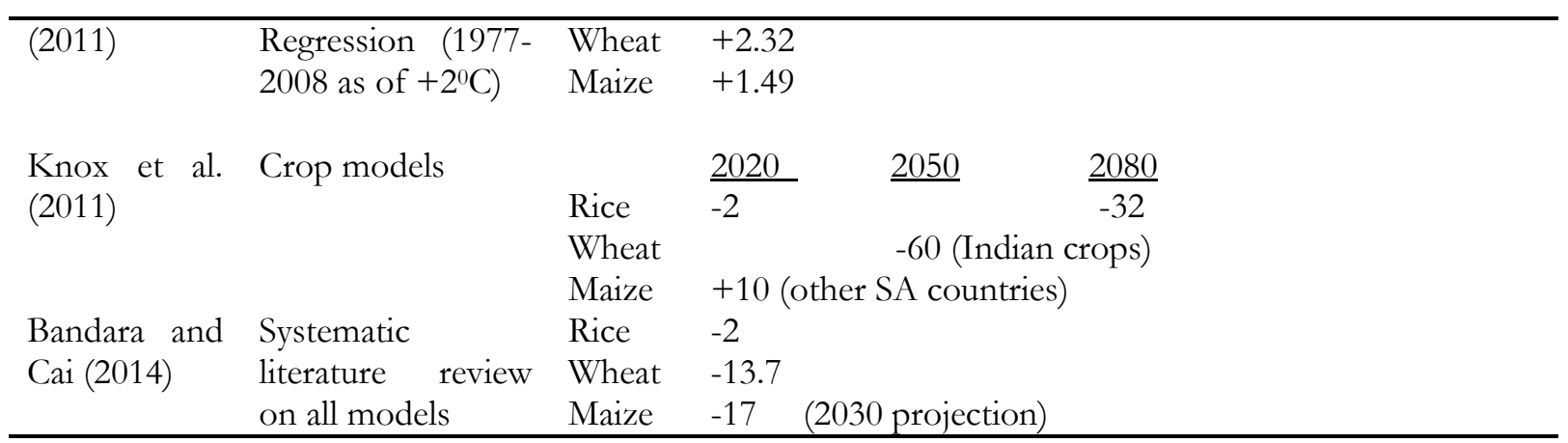

Note: This table is mainly based on a systematic literature survey

\section{Empirical model and framework}

On the one hand, it is not hard to comprehend the qualitative impacts of climate change when household economic parameters are not included. On the other hand, when quantifying climate-change impacts and possible adaptation strategies, including households' economic parameters, it is difficult to assess the effects of all factors that are responsible for climate change. CGE models have frequently been used to model the behaviour and decisions of households. However, the recent trend of using global CGE models (e.g., Hertel et al., 2010; Müller \& Robertson, 2014; Nelson \& Shively, 2014) and South Asian CGE models (e.g., Ahmed \& Suphachalasai, 2014; Bandara \& Cai, 2014) to evaluate climate-change impacts in agriculture has created a substantial literature gap in assessing possible adaptations. Thus, a single-country, multi-household CGE model with the appropriate inclusion of potential adaptations in agriculture can capture the discrepancies in income and consumption due to climate-changeinduced changes in agriculture.

This paper uses a comparative-static CGE model, following the tradition of the applied general equilibrium approach pioneered by Dixon et al. (1982), although its precise specification is more closely related to the South African CGE model developed by Horridge et al. (1995). As in any generic CGE model, producers are assumed to maximise profits subjected to resource constraints and consumers are assumed to maximise utility subject to budget constraints. Moreover, this model also follows the neoclassical assumptions: export demand is negatively related to export prices; government expenditure is exogenously determined; consumers, producers and other agents are assumed to be price takers, not price makers; and the entire product and factor markets follow the market-clearing assumption of demand equals supply.

For the purpose of simulation, this model consists of 57 industries, 57 commodities, 3 factors, 7 household groups and 10 skill/occupations type (see Appendix B and C). Household incomes are determined by their possession of 3 production factors (land, labour and capital) 
and the market returns to these factors. The model comprises a set of nested CES functions for specifying production technologies and consumer demands for final goods and services. Households, government, enterprises and the rest of the world are the major agents that demand the final goods for their consumption. In the same way, we specify a CES function for an intermediate mix. Production of final goods and services is the combination of intermediate inputs and primary factors. The primary factors (land, labour and capital) are aggregated through a CES function with a sub-set of CES functions for different types of occupations and a CET function for land supply.

In order to incorporate the key characteristics of household types, occupational skills and their linkages to the rest of the economy, we extend the basic CGE model in two dimensions. First, given that a comparative analysis of climate-change impacts is important for identifying winners and losers, we follow Horridge et al. (1995) and introduce seven types of households on the basis of their characteristics, such as hectares of agricultural land that they hold and household head's level of education (see Appendix B). The purpose of defining household groups in this way is to introduce heterogeneity with respect to urban/rural livelihood, mountain/hill/lowland topography, and high/low education. In doing so, we use the Nepalese National Living Standard Survey database (CBS, 2011) to disaggregate households' final consumption and returns from primary factors. Second, to allow for differential effects in the employment of skill categories, we introduce 10 occupation types and explicitly model the heterogeneity of levels of income.

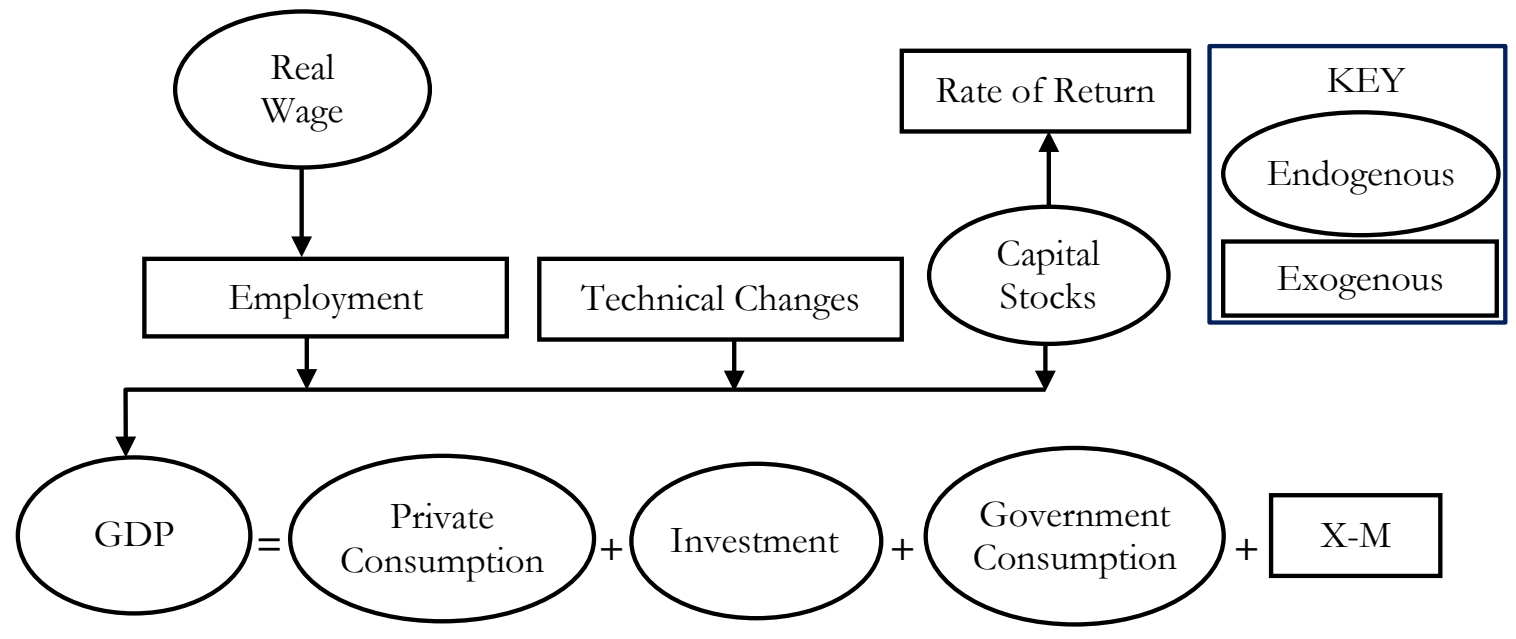

Diagram 1. Long-run closure used in the model. Note: The exogenous and endogenous variables used in this model closure are based on recent ORANI-G version.

In this model, "Rest of the world" is an agent that links the exports and imports of goods and services with the national economy. In this case, a CES function is also specified to represent 
consumers' choices/decisions between domestic and imported goods, aggregating the final demand composite. The relative prices of goods and services are determined on the basis of real exchange rate as a numeraire such that income in household level is influenced by relative prices rather than absolute ones. To represent that saving equal investment, savings-driven income flow is assumed analogous to investments that are used only for final commodities. Capital and labour are perfectly mobile within a country but completely immobile in the rest of the world. As there is a scientific consensus that the impacts of climate change can be realized distinctly within a $30-40$ year period, a long-run closure (see Fig. 1) is set for our model simulation to avoid the uncertainty of transitional projection, and to evade the dangers of disequilibrium in the neoclassical approach [such as the issue raised by Scrieciu (2007)]. At the macro-level, GDP, household consumption, investment, public spending, real wages and capital stock are treated as endogenous. Total employment, technical changes, capital rate of return and terms of trade are treated as exogenous.

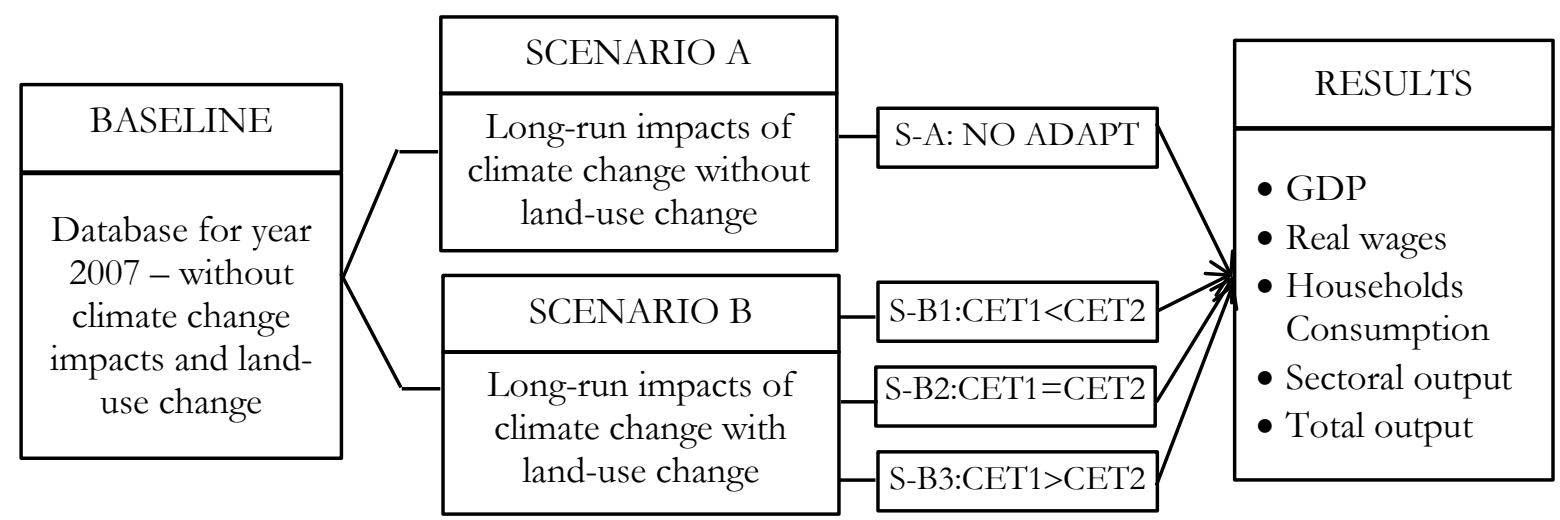

Diagram 2. Conceptual framework of the experiment Note: $\mathrm{S}=$ simulation

In order to address the link between climate change-induced impacts in agricultural productivity and other parameters in the overall economy, we focus on the 14 agricultural sectors $^{3}$ (out of the 57 sectors in the GTAP database - see Appendix C) in Nepal. From the impact assessment-related literature, an average productivity shocks of rice, wheat, maize and other agricultural products are employed in the CGE model developed for this study (Table 1). The reasons for taking an average of impacts are, firstly, to address the irregular trend of assessment developed in previous literature. Secondly, the previous assessments have a different time frame of impact assessment, with the risk of extremely low or high estimations. Two scenarios are developed for the simulations in this paper. Diagram 2 presents the conceptual

\footnotetext{
3 They are rice, wheat, cereal grains, vegetables fruits and nuts, oil seeds, sugar cane sugar beet, plant based fibers, other crops, bovine cattle sheep goats horses, animal products, raw milk, wool silk worms, forestry and fishing.
} 
framework. Scenario A assumes that normal land allocation prevails and there is no change in land supply with respect to impacts of climate change. Scenario B has three simulations, assuming that the land is mobile among industries. The first simulation assumes that the CET of paddy (CET1) is less than the CET of other agricultural sectors (CET2); the second that CET1 is equal to CET2; and the third that CET1 is greater than CET2 (the framework of nested CET parameters is discussed in the following section). The results are compared and analysed on the basis of changes in key macro-variables such as real GDP, real wages, household consumption and industry output.

The proposed model adds an important land supply equation to the original ORANI-G model, including linearisation of profit maximisation subject to the cost of inputs. As land rentals across different land usage suggest that land does not move freely between alternatives, the only way to model land supply is to use a CET function. In doing so, we assume that producers seek to maximise returns from land producing given levels of output by supplying extra land to industries that experience significantly lower impacts of climate change.

The equation for the above problem can be written as follows:

$$
x_{k}=z-\sigma\left(p_{a v e}-p_{k}\right)
$$

Where $z$ is the total agricultural land, $x_{k}$ is the land allocated for a particular industry, $k$, and maximising the return from a unit plot of land is the principal objective of the producers. This is determined by farmers' decisions with respect to the degree of impact of climate change to that particular crop. $\sigma$ is the CET parameter that is externally supplied in the model on the basis of agronomic feasibility. Mathematically, $\sigma=1 /(\rho-1)$. Similarly, $p_{k}$ is the profitability per unit of effective land and $p_{a v e}$ is the average profitability per unit of effective land. Mathematically, $p_{\text {ave }}=\sum_{i} S_{i} p_{i}$, where, $S_{i}$ is the share of industry, $i$, in total land profitability.

A problem with the CET function is that it implies that the elasticity of transformation is identical for all pairs of crops (Powell \& Gruen, 1968). It is almost impossible to use the above equation to address the heterogeneity of several agricultural sectors. The only way to deal with this problem is by arranging the CET function in a nest. In doing so, the arguments of the function are split into pairs. Again, a major problem in nested CET functions is how to choose the pairs in a nest: this depends on agronomic characteristics and constraints. Because of these constraints, a set of pairs may include different crops in different agro-ecological zones. To address this issue, our model has used a set of CET parameters to test both the positive and negative impacts on the overall economy. 
As the main objective of this paper is to develop and test a general framework of land-use change, we develop a simple nest of CET functions with two levels. Out of 14 agricultural sectors, a nest of the paddy sector and other agricultural sectors is developed. A set of CET values is used to model the transferring the paddy land into the other 13 agricultural lands and vice versa. Similarly, a set of CET values is used to model transferring land between other pairs of crops within the 13 agricultural sectors. Although previous studies (e.g., Keeney \& Hertel, 2009; Palatnik et al., 2011) have attempted to develop a nested set of agricultural sectors, their results are seriously limited by not testing a range of CET values for a single pair. It is difficult to recommend a land-use change framework without testing a set of feasibility parameters. Therefore, we develop a wide range of CET values, from highly inelastic to elastic to highly elastic, to test their feasibility and to recommend a framework to the local farmers of Nepal.

\section{Effects of land-use change: simulation results}

The results obtained from the simulations of the impacts of climate change and land-use change on Nepalese agriculture are analysed in two different stages: (1) changes in the overall macro-variables; and (2) impacts at the household level. As mentioned in the methodology section, every result is compared to the baseline status and reported as a percentage change. Deviation of the variables from the base year (a year without climate change and land-use change; our model uses 2007 as the base year) to a future year (which is determined with distinct climate-change impacts and land-use change; our model uses 2080) is evaluated. As demonstrated in Diagram 2, four distinct climate change scenarios are simulated. In scenario A, the effects of climate change are analysed assuming that normal land allocation prevails and that the effects of land-use change among agricultural sectors can be ignored. In scenario B, crop switching by farmers to increase the availability of land to crops less impacted by climate change is represented by changes in the amount of farmland under less-impacted crops. As discussed in the methodology section, scenario B is analysed with three different simulations on the basis of CET ratio: $\mathrm{B} 1$ has CET1 < CET2, B2 has CET1 = CET2 and B3 has CET1 > CET2 (CET value ranges from 0.5 to 20$)$. 


\section{Table 2}

Projections of percentage change in macro-variables under different climate change and land-use change scenarios

\begin{tabular}{lllll}
\hline Macro-variables & $\begin{array}{l}\text { Simulation 1 } \\
\text { Without } \\
\text { climate change } \\
\text { adaptation }\end{array}$ & $\begin{array}{l}\text { Simulation 2 } \\
\text { With climate } \\
\text { change } \\
\text { adaptation and } \\
\text { CET1<CET2 }\end{array}$ & $\begin{array}{l}\text { Simulation 3 } \\
\text { With climate } \\
\text { change } \\
\text { adaptation and } \\
\text { CET1=CET2 }\end{array}$ & $\begin{array}{l}\text { Simulation } 4 \\
\text { With climate } \\
\text { change } \\
\text { adaptation and }\end{array}$ \\
& & -11.042 & -8.301 & -7.067 \\
\hline Real gross domestic product & -8.315 & 15.263 & 7.212 & 5.792 \\
Consumer price index & 7.181 & -17.839 & -10.851 & -7.585 \\
Real wage & -11.061 & -7.841 & -7.489 & -6.740 \\
Household consumption & -7.534 & 3.455 & 1.291 & 1.733 \\
Terms of trade & 1.162 & & & \\
\hline
\end{tabular}

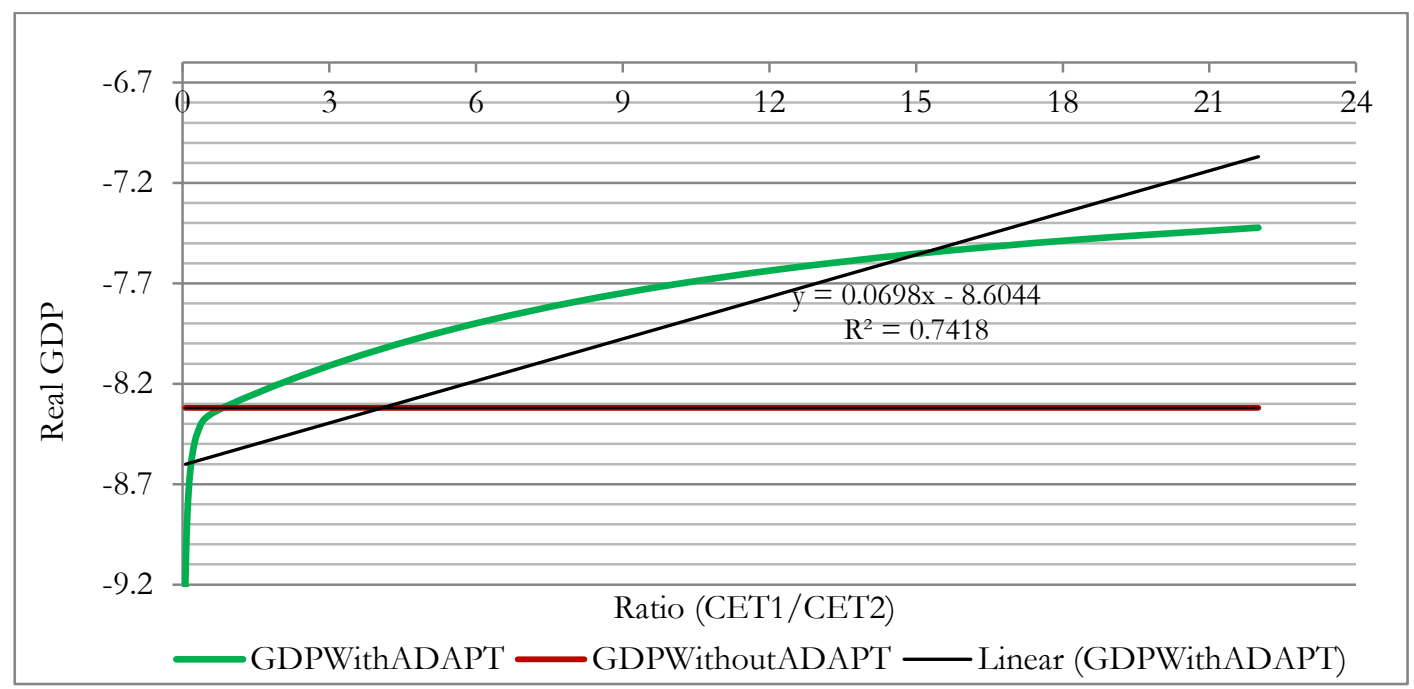

Fig. 1. Trend of change in real GDP from baseline in Nepal with increasing CET ratio (CET1/CET2) as a result of climate change with and without land-use change (unit $=\%$ )

Real GDP is an important tool for evaluating a change in the overall economy due to the impacts of climate change and land-use change on agriculture. Moreover, the use of real GDP in terms of estimating changes in the Nepalese economy is important, as agriculture represents around $36 \%$ of the national GDP. Table 2 shows that, without land-use change, the projected impact of climate change on agricultural productivity affects real GDP negatively. In scenario A, the real GDP is expected to decrease by $8.31 \%$. A major factor of such a significant fall in GDP is the substantial fall in output of many agricultural products and other industrial outputs related to agriculture. Regarding scenario B, the change in real GDP depends on the CET ratio. The higher the CET ratio, the less the impacts of climate change on real GDP. As shown in Fig. 1, an increasing trend of CET ratio (CET1:CET2) improves the real GDP. This is because a higher 
CET ratio means that farmers are able to allocate more land to paddy than to other agricultural sectors on the basis of the degree of climate-change impacts in these respective crops.

\section{Table 3}

Projections of percentage change in industry output and price of commodities under different climate change and land-use change scenarios

\begin{tabular}{|c|c|c|c|c|c|c|c|c|}
\hline \multirow[t]{2}{*}{ Sectors } & \multicolumn{2}{|c|}{$\begin{array}{l}\text { Simulation } 1 \\
\text { Without climate } \\
\text { change adaptation }\end{array}$} & \multicolumn{2}{|c|}{$\begin{array}{l}\text { Simulation } 2 \\
\text { With climate } \\
\text { change adaptation } \\
\text { CET1<CET2 }\end{array}$} & \multicolumn{2}{|c|}{$\begin{array}{l}\text { Simulation } 3 \\
\text { With climate } \\
\text { change } \\
\text { adaptation } \\
\text { CET1=CET2 }\end{array}$} & \multicolumn{2}{|c|}{$\begin{array}{l}\text { Simulation } 4 \\
\text { With climate } \\
\text { change adaptation } \\
\text { CET1>CET2 }\end{array}$} \\
\hline & Output & Price & Output & Price & Output & Price & Output & Price \\
\hline Agriculture & -9.872 & 20.956 & -11.590 & 37.675 & -9.799 & 20.896 & -8.734 & 18.035 \\
\hline Mining & -1.859 & -1.731 & -9.925 & 4.556 & -6.998 & 1.654 & -6.201 & 1.793 \\
\hline Manufacture & -8.458 & 4.261 & -12.933 & 6.106 & -8.527 & 4.133 & -7.731 & 2.626 \\
\hline Utilities & -6.631 & -0.484 & -9.898 & 1.661 & -6.683 & -0.343 & -5.957 & 0.203 \\
\hline Services & -6.211 & -0.986 & -9.791 & 2.1938 & -6.295 & -0.785 & -5.747 & 0.034 \\
\hline
\end{tabular}

Overall outputs of other sectors are likely to be affected according to climate changeinduced productivity loss in Nepalese agriculture. Table 3 shows the decrease in sectoral output and the improvement that can be achieved with land-use change. The manufacturing sector in particular is expected to be highly influenced by climate-change impacts, as this sector primarily depends on agricultural raw materials and products.

\section{Table 4}

Projections of percentage change in consumer price index (CPI) and household consumption of commodities under different climate change and land-use change scenarios

\begin{tabular}{|c|c|c|c|c|c|c|c|c|}
\hline \multirow[t]{2}{*}{ Households } & \multicolumn{2}{|c|}{$\begin{array}{l}\text { Simulation } 1 \\
\text { Without } \\
\text { climate change } \\
\text { adaptation }\end{array}$} & \multicolumn{2}{|c|}{$\begin{array}{l}\text { Simulation } 2 \\
\text { With climate } \\
\text { change } \\
\text { adaptation } \\
\text { CET1<CET2 }\end{array}$} & \multicolumn{2}{|c|}{$\begin{array}{l}\text { Simulation } 3 \\
\text { With climate } \\
\text { change } \\
\text { adaptation } \\
\text { CET1=CET2 }\end{array}$} & \multicolumn{2}{|c|}{$\begin{array}{l}\text { Simulation } 4 \\
\text { With climate } \\
\text { change } \\
\text { adaptation } \\
\text { CET1>CET2 }\end{array}$} \\
\hline & $\mathrm{CPI}$ & $\mathrm{CON}$ & $\mathrm{CPI}$ & $\mathrm{CON}$ & CPI & $\mathrm{CON}$ & $\mathrm{CPI}$ & $\mathrm{CON}$ \\
\hline Rural land less & 7.18 & -7.68 & 15.26 & -8.05 & 7.21 & -7.65 & 5.79 & -6.98 \\
\hline Rural land small & 7.17 & -6.33 & 15.22 & -8.02 & 7.20 & -6.23 & 5.78 & -4.76 \\
\hline Rural land medium & 7.17 & -5.87 & 15.21 & -4.68 & 7.19 & -5.82 & 5.78 & -5.48 \\
\hline Rural land large & 7.17 & -9.15 & 15.21 & -2.91 & 7.20 & -5.90 & 5.79 & -6.33 \\
\hline Urban low education & 7.18 & -9.20 & 15.30 & -12.42 & 7.21 & -9.05 & 5.79 & -7.32 \\
\hline Urban medium education & 7.18 & -9.20 & 15.30 & -10.41 & 7.21 & -9.15 & 5.80 & -8.17 \\
\hline Urban high education & 7.18 & -8.63 & 15.28 & -8.37 & 7.21 & -8.62 & 5.80 & -8.12 \\
\hline
\end{tabular}


Note: $\mathrm{CPI}=$ consumer price index and $\mathrm{CON}=$ household consumption

As overall sectoral outputs decrease substantially due to climate change, commodity prices are expected to increase significantly. Table 3 shows the estimated increase in prices of agricultural and other commodities in both scenarios. As climate change has a huge impact on Nepalese agriculture, the results show a significant increase in the prices of agricultural commodities in particular; in fact, it would not be surprising if there were a huge crisis in agricultural products in the future. Moreover, although rice is a major part of agricultural economy in Nepal, cereal crops also play an important role in rural livelihoods, especially in the mid-hills and rural mountains (CBS, 2012). The expected increase in the price of cereal crops in Nepal will obviously create a huge food security problem in the future. Table 4 clearly depicts the impact of increased prices on the consumer price index for all household groups. However, if farmers are able to use more land to paddy, the expected increase in price of commodities would slow down and reduce the risk of food insecurity.

A substantial decrease in sectoral outputs, primarily in agricultural products, influences household income and consumption. As real GDP (from the expenditure side-see the last row of Diagram 1) is determined by the sum of household consumption, investment, government expenditure and net exports, the significant decrease in household consumption results in a huge decline in real GDP. Overall household consumption, which is shown in Table 2, clearly illustrates the important role of household expenditure in maintaining a progressive GDP. To understand the full effects of climate change-induced productivity loss, it is important to see the differences in impacts between various households. Table 4 shows the changes in consumption for different household groups. The Table clearly differentiates the spread of impacts, as urban households are expected to experience a significantly greater decrease in consumption than rural ones. This is because urban households do not produce agricultural commodities and depend on highly priced products from the producers, who primarily belong to rural households. However, the patterns of consumption are projected to improve if farmers allocate land to paddy as expected. 


\section{Table 5}

Projections of percentage change in household labour income and total household income under different climate change and land-use change scenarios

\begin{tabular}{|c|c|c|c|c|c|c|c|c|}
\hline \multirow[t]{2}{*}{ Households } & \multicolumn{2}{|c|}{$\begin{array}{l}\text { Simulation } 1 \\
\text { Without climate } \\
\text { change } \\
\text { adaptation }\end{array}$} & \multicolumn{2}{|c|}{$\begin{array}{l}\text { Simulation } 2 \\
\text { With climate } \\
\text { change } \\
\text { adaptation } \\
\text { CET1 }<\text { CET2 }\end{array}$} & \multicolumn{2}{|c|}{$\begin{array}{l}\text { Simulation } 3 \\
\text { With climate } \\
\text { change } \\
\text { adaptation } \\
\text { CET1=CET2 }\end{array}$} & \multicolumn{2}{|c|}{$\begin{array}{l}\text { Simulation } 4 \\
\text { With climate } \\
\text { change } \\
\text { adaptation } \\
\text { CET1>CET2 }\end{array}$} \\
\hline & $\mathrm{LI}$ & TI & LI & TI & LI & $\mathrm{TI}$ & $\mathrm{LI}$ & $\mathrm{TI}$ \\
\hline Rural land less & -5.71 & -10.31 & -5.65 & -13.74 & -5.48 & -10.21 & -3.51 & -8.39 \\
\hline Rural land small & -2.09 & -8.98 & -1.01 & -13.72 & -1.83 & -8.81 & 0.25 & -6.19 \\
\hline Rural land medium & -1.38 & -8.50 & -0.07 & -10.45 & -1.11 & -8.40 & 0.98 & -6.90 \\
\hline Rural land large & -1.96 & -8.52 & -0.79 & -8.712 & -1.69 & -8.48 & 0.37 & -7.74 \\
\hline Urban low education & -5.51 & -11.75 & -5.43 & -18.01 & -5.29 & -11.59 & -3.31 & -8.73 \\
\hline Urban medium education & -7.19 & -11.80 & -7.34 & -16.04 & -6.98 & -11.69 & -4.97 & -9.57 \\
\hline Urban high education & -7.98 & -11.25 & -8.16 & -14.04 & -7.77 & -11.16 & -5.69 & -9.52 \\
\hline
\end{tabular}

Note: $\mathrm{LI}=$ labour income and TI $=$ total household income

To understand the considerable loss in GDP requires an estimation of the change in the individual parameters that determine the real GDP from the income side: land rents, labour wages, capital interests, profits and taxes. The major components of household income are rental income, wages and interest. We have to investigate the income of rural and urban households separately. As total employment is constant in the long run closure of the model, labour from other sectors moves to agriculture-based industries (see Table 6). As the cost of living goes up due to extreme inflationary prices, overall real wages decrease significantly. We have noted the huge decrease in sectoral output in manufacturing and services (see Table 3), labour income in urban households will decrease considerably, more so than in rural households (see Table 5). However, land-use change to climate-smart crops such as paddy can improve the loss in sectoral outputs and recover some of the household income and expenditure.

\section{Table 6}

Projections of percentage change in employment under different climate change and land-use change scenarios

\begin{tabular}{|c|c|c|c|c|}
\hline Occupations & $\begin{array}{l}\text { Simulation } 1 \\
\text { Without } \\
\text { climate change } \\
\text { adaptation }\end{array}$ & $\begin{array}{l}\text { Simulation } 2 \\
\text { With climate } \\
\text { change } \\
\text { adaptation } \\
\text { CET1 }<\text { CET2 }\end{array}$ & $\begin{array}{l}\text { Simulation } 3 \\
\text { With climate } \\
\text { change } \\
\text { adaptation } \\
\text { CET1=CET2 }\end{array}$ & $\begin{array}{l}\text { Simulation } 4 \\
\text { With climate } \\
\text { change } \\
\text { adaptation } \\
\text { CET1>CET2 }\end{array}$ \\
\hline Self employed & -3.61 & -4.81 & -3.68 & -3.95 \\
\hline High skilled professionals & -4.41 & -5.14 & -4.43 & -4.26 \\
\hline
\end{tabular}




\begin{tabular}{lllll}
\hline Medium skilled professionals & -3.23 & -3.77 & -3.25 & -3.18 \\
NGO/INGO clerks & -4.40 & -4.90 & -4.39 & -4.08 \\
Industry workers & 1.02 & 0.78 & 1.01 & 1.04 \\
Art and crafts & -2.91 & -4.34 & -3.00 & -3.28 \\
Informal workers & -0.87 & -1.29 & -0.87 & -0.74 \\
Agriculture owners & 2.67 & 3.17 & 2.67 & 2.52 \\
Agriculture workers & 2.87 & 3.49 & 2.91 & 2.97 \\
Agriculture subsistence farmers & 7.24 & 9.17 & 7.31 & 7.38 \\
\hline
\end{tabular}

As evidenced from above, land-use change to climate-smart crops in Nepal is expected to improve the climate change-induced productivity losses and negative impacts on the overall economy. These improvements spread to sectors beyond the agriculture-related industries, such as manufacturing and services. As Nepalese manufacturing and service sectors are linked with agricultural products, a small improvement in agricultural productivity creates multiplier effects in the overall economy. Table 3 also predicts that manufacturing outputs will decrease by around $8 \%$ due to crop productivity loss when normal land allocation prevails. However, a significant increase in output can be expected after land-use change. A similar situation is expected in the utility and services sectors if farmers keep allocating more land to climate-smart crops.

\section{Discussion and conclusions}

Using a country-specific CGE model of the Nepalese economy, this paper has explored the macro- and micro-economic effects of climate-change impacts and land re-allocation in Nepalese agriculture. As mentioned in the results section, the simulation results of this study revealed that Nepalese agriculture will have severe impacts if land re-allocation is not trialled and implemented in the future. If the trend of allocating land to crops that suffer huge impacts from climate change continues, the resulting massive increase in commodity prices will pose great challenges for rural smallholders' livelihoods. As an outcome of these results, real GDP is expected to decrease markedly.

The results of this study are highly consistent with the results of previous studies. As Nepalese agriculture is the most affected among South Asian countries-according to Bandara and Cai (2014, p. 459), among others-the results of the simulation described above show that climate-induced reduction in food production is projected to put an upward pressure on food prices, resulting in a food security problem in Nepal. The prices of rice, wheat and cereal grains-three major staple foods in Nepal-are expected to rise significantly at the rate of around $26 \%, 36 \%$ and $44 \%$ per annum respectively. As Nepal imports most of its staples foods 
from South Asian countries, the situation will become challenging as global food prices are expected to increase significantly in the future (FAO, 2015; Hertel et al., 2010).

Some key policy implications related to climate change, particularly from a larger perspective, can be drawn from this study. Nepal, as a member of the least-developed countries, can expect the impacts of climate change to be severe. Mainly because of its static adaptation capacity, ${ }^{4}$ the vulnerability projection according to the A2 emission scenario in 2050 (IPCC, 2000) places Nepal in the significantly vulnerable category. Although farmers have already initiated some useful adaptation practices on their own, without any support from government or any other organisations, it is urgent to initiate large-scale planned strategies to support them. Based on the results of this study, as well as the likelihood of more frequent flash floods in low-land paddy farms and serious landslides in hilly maize farms in Nepal, it seems wise to invest more in controlling excess water flows and on forest management technology. In addition, serious consideration should be given to measures designed to prevent, mitigate and adapt to water deficiency in Nepalese cropping agriculture. As Salami, Shahnooshi, and Thomson (2009) suggest, cropping rotation and changes in the cropping-calendar, such as fairly simple modifications in vegetable growing (changed planting dates, and different maturity-date cultivars), can reduce likely climate change-induced losses in future decades.

To conclude, future research is recommended to address the limitations of this study. Our study has not explored the bio-physical aspects of climate-change impacts in detail, including those determining the actual cost of damage to crops and human capital, such as impacts in biophysical requirements due directly or indirectly to imbalances in water, or to labour productivity, etc. Therefore, a study to evaluate all the factors responsible for productivity loss due to climate change, and the adaptation practices that have been started in Nepal, is required. A numerical assessment of the impacts and possible adaptation to climate change would require a much expanded modelling framework, and/or considered assumptions of the extent and distribution of such problems. Despite this study's limitations, its results have evidenced that serious policy planning and implementation of adaptation strategies in the near future is required to help reduce the negative impact of climate change on agriculture and to reduce the level of poverty among all household groups.

\footnotetext{
${ }^{4}$ According to the vulnerability projection report, vulnerability is a function of exposure, sensitivity and adaptive capacity.
} 


\section{Appendix A}

Figure A1 Projection of change in daily temperature and precipitation (1999 to 2080)

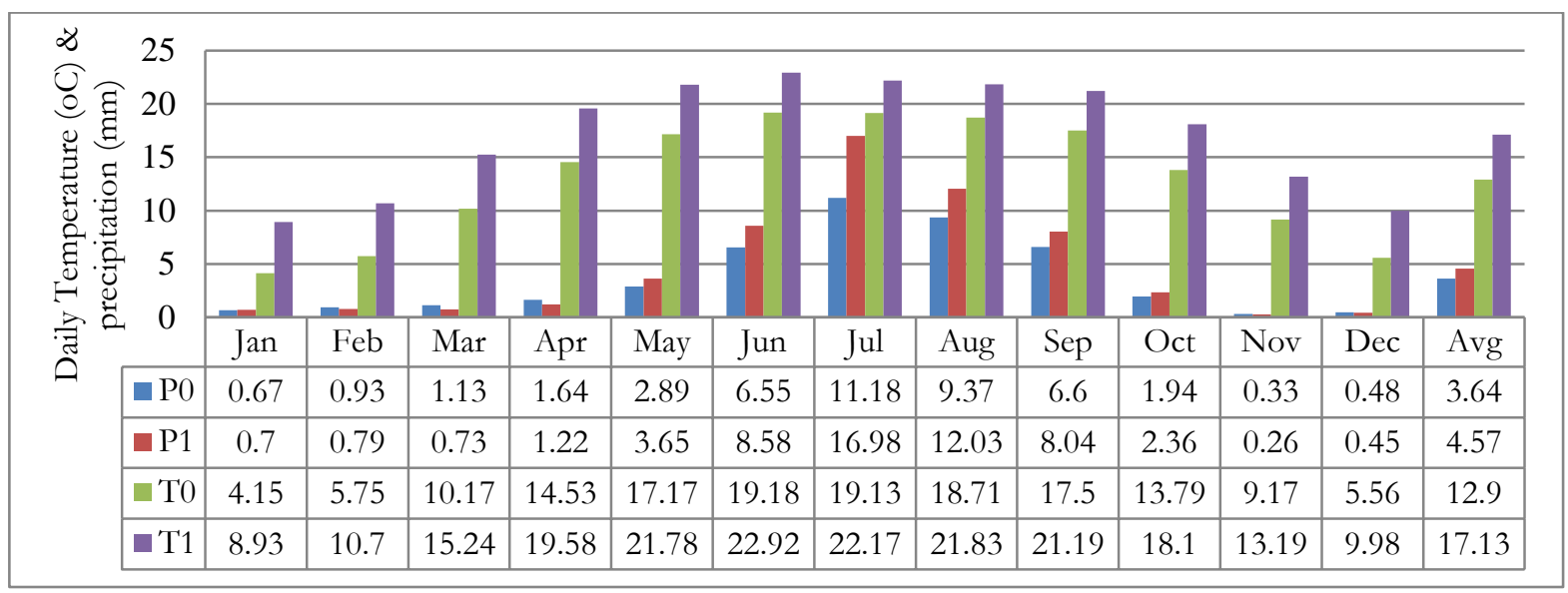

Note: The Figure is mainly based on projection by Cline (2007). P0 = daily precipitation of base year$1999, \mathrm{P} 1=$ projected daily precipitation of $2080, \mathrm{~T} 0=$ temperature of base year- 1999 and $\mathrm{T} 1=$ projected temperature of 2080.

\section{Appendix B}

Table B1 Household groups and occupation types

\begin{tabular}{ll}
\hline Grouping & Income groups and their characteristics \\
\hline Households & 1. Rural landless farmer \\
& 2. Rural land small farmer (less than 0.5 Bigha*) \\
3. Rural land medium farmer (between 0.51 and 2.50 Bigha) \\
4. Rural land large farmer (more than 2.51 Bigha) \\
5. Urban low education (household head having less than class/grade 10 \\
education) \\
6. Urban medium education (household head having both secondary school \\
certificate and higher secondary certificate) \\
7. Urban high education (household head having bachelor and high degrees) \\
1. Self-employed labourers \\
2. High skilled professionals and managers \\
3. Medium skilled professionals and technicians \\
4. Government and non-government office clerks (employees) \\
5. Workers (transport, mechanics and other industrial workers) \\
6. Artisans and handicraftsmen \\
7. Informal (street-vendors and non-economic services nes) \\
8. Agricultural owners/administrators \\
9. Agricultural workers \\
10. Agriculture subsistence farmers
\end{tabular}

Note: Bigha* is a unit of land mostly used in the rural part of Nepal. One Bigha $=0.16055846$ Hectares. 


\section{Appendix C}

Table C1 List of industries

\begin{tabular}{|c|c|}
\hline Sectors & Industries \\
\hline Agriculture & $\begin{array}{l}\text { 1. Paddy rice } 2 \text {. Wheat 3. Cereal grains nec } 4 \text {. Vegetables, fruit and nuts } 5 \text {. Oil } \\
\text { seeds } 6 \text {. Sugar cane, sugar beet } 7 \text {. Plant-based fibers } 8 \text {. Crops nec } 9 \text {. Bovine } \\
\text { cattle, sheep and goats, horses } 10 \text {. Animal products nec } 11 \text {. Raw milk } 12 . \\
\text { Wool, silk-worm cocoons } 13 \text {. Forestry } 14 \text {. Fishing }\end{array}$ \\
\hline Mining & 15. Coal 16. Oil 17. Gas 18. Minerals nec \\
\hline Manufacturing & $\begin{array}{l}\text { 19. Bovine cattle, sheep and goat, horse meat products } 20 \text {. Meat products nec } \\
\text { 21. Vegetable oils and fats } 22 \text {. Dairy products } 23 \text {. Processed rice } 24 \text {. Sugar } 25 . \\
\text { Food products nec 26. Beverages and tobacco products } 27 \text {. Textiles } 28 \\
\text { Wearing apparel 29. Leather products } 30 \text {. Wood products } 31 \text {. Paper products, } \\
\text { publishing 32. Petroleum, coal products 33. Chemical, rubber, plastic } \\
\text { products 34. Mineral products nec } 35 \text {. Ferrous metals } 36 \text { Metals nec } 37 . \\
\text { Metal products 38. Motor vehicles and parts 39. Tranport equipment nec } 40 . \\
\text { Electronic equipment 41. Machinery and equipment nec } 42 \text {. Manufacturers } \\
\text { nec }\end{array}$ \\
\hline Utilities & 43. Electricity 44. Gas manufacture, distribution 45. Water \\
\hline Services & $\begin{array}{l}\text { 46. Construction 47. Trade 48. Transport nec 49. Water transport 50. Air } \\
\text { transport 51. Communication } 52 \text {. Financial services nec 53. Insurance } 54 . \\
\text { Business services nec 55. Recreational and other services } 56 \text {. Public } \\
\text { administration and defense, education, health } 57 \text {. Dwellings }\end{array}$ \\
\hline
\end{tabular}

Note: This Table is based on global trade analysis project (GTAP) database for the base year- 2007

\section{References}

Ahmed, M., \& Suphachalasai, S. (2014). Assessing the Costs of Climate Change and Adaptation in South Asia. Mandaluyong City, Philippines: Asian Development Bank.

Arndt, C., Robinson, S., \& Willenbockel, D. (2011). Ethiopia's growth prospects in a changing climate: A stochastic general equilibrium approach. Global Environmental Change, 21(2), 701-710. doi: http://dx.doi.org/10.1016/i.gloenvcha.2010.11.004

Arndt, C., Strzepeck, K., Tarp, F., Thurlow, J., Fant, C. I. V., \& Wright, L. (2011). Adapting to climate change: an integrated biophysical and economic assessment for Mozambique. Sustainability Science, 6(1), 7-20. doi: http://dx.doi.org/10.1007/s11625-010-0118-9

Auffhammer, M., Ramanathan, V., \& Vincent, J. R. (2012). Climate change, the monsoon, and rice yield in India. Climatic Change, 111(2), 411-424. doi: 10.1007/s10584-011-0208-4

Bandara, J. S., \& Cai, Y. (2014). The impact of climate change on food crop productivity, food prices and food security in South Asia. Economic Analysis and Policy, 44(4), 451-465. doi: http://dx.doi.org/10.1016/i.eap.2014.09.005

Bezabih, M., Chambwera, M., \& Stage, J. (2011). Climate change and total factor productivity in the Tanzanian economy. Climate Policy, 11(6), 1289-1302.

Bosello, F., \& Zhang, J. (2005). Assessing Climate Change Impacts: Agriculture (C. C. M. a. Policy, Trans.) (Vol. NOTA DI LAVORO 94.2005): Fondazione Eni Enrico Mattei.

Byjesh, K., Kumar, S., \& Aggarwal, P. (2010). Simulating impacts, potential adaptation and vulnerability of maize to climate change in India. Mitigation and Adaptation Strategies for Global Change, 15(5), 413431. doi: http://dx.doi.org/10.1007/s11027-010-9224-3 
CBS. (2011). Nepal Living Standards Survey (Vol. 2): Central Bureau of Statistics.

CBS. (2012). Statistical Information on Nepalese Agriculture 2011/2012: Central Bureau of Statistics, Nepal.

CBS. (2014). Statistical pocket book of Nepal. Kathmandu, Nepal: Central Bureau of Statistics, Government of Nepal.

Chalise, S., Maraseni, T. N., \& Maroulis, J. (2015). Adapting to climate variability: the views of peasant farmers in Nepal. International Journal of Global Warming, 7(3), 380-394. doi: http://dx.doi.org/doi:10.1504/IJGW.2015.069369

Claessens, L., Antle, J. M., Stoorvogel, J. J., Valdivia, R. O., Thornton, P. K., \& Herrero, M. (2012). A method for evaluating climate change adaptation strategies for small-scale farmers using survey, experimental and modeled data. Agricultural Systems, 111, 85-95. doi: http://dx.doi.org/10.1016/j.agsy.2012.05.003

Cline, W. R. (2007). Global Warming and Agriculture, Impact Estimates by Country

Dixon, P. B., Parmenter, B. R., Sutton, J., \& Vincent, D. P. (1982). ORANI, a multisectoral model of the Australian economy. Amsterdam ; New York : New York, N.Y: North-Holland Pub. Co. ; Sole distributors for the U.S.A. and Canada, Elsevier Science Pub. Co.

Eboli, F., Parrado, R., \& Roson, R. (2010). Climate-change feedback on economic growth: explorations with a dynamic general equilibrium model. Environment and Development Economics, 15(5), 515-533. doi: http://dx.doi.org/10.1017/S1355770X10000252

Elbehri, A., \& Burfisher, M. (2015). Economic modelling of climate impacts and adaptation in agriculture: a survey of methods, results and gaps. In A. Elbehri (Ed.), Climate Change and Food Systems - Global Assessments and Implications for Food Security and Trade. Rome: FAO.

Esham, M., \& Garforth, C. (2013). Agricultural adaptation to climate change: insights from a farming community in Sri Lanka. Mitigation and Adaptation Strategies for Global Change, 18(5), 535-549. doi: http://dx.doi.org/10.1007/s11027-012-9374-6

FAO. (2015). Climate Change and Food Systems - Global Assessments and Implications for Food Security and Trade. Rome: FAO.

Fujimori, S., Hasegawa, T., Masui, T., \& Takahashi, K. (2014). Land use representation in a global CGE model for long-term simulation: CET vs. logit functions. Food Security, 1-15. doi: http://dx.doi.org/10.1007/s12571-014-0375-z

Gurung, G. B., \& Bhandari, D. (2009). Integrated Approach to Climate Change Adaptation. Journal of Forest and Livelihood 8(1), 90-98.

Hertel, T. W., Burke, M. B., \& Lobell, D. B. (2010). The poverty implications of climate-induced crop yield changes by 2030. Global Environmental Change, 20(4), 577-585. doi: http://dx.doi.org/10.1016/i.gloenvcha.2010.07.001

Hertel, T. W., Rose, S., Tol, R. S. J., Taylor, \& Francis. (2009). Economic analysis of land use in global climate change policy (Vol. 14.). New York; London: Taylor and Francis.

Horridge, M., Parmenter, B. R., Cameron, M., Joubert, R., Suleman, A., \& de Jongh, D. (1995). The macroeconomic, industrial, distributional and regional effects of government spending programs in South Africa Working Paper: Monash University.

Iglesias, A., \& Rosensweig, C. (2010). Effects of Climate Change on Global Food Production from SRES Emissions and Socioeconomic Scenarios. Palisades, NY: NASA Socioeconomic Data and Applications Center (SEDAC).

IPCC. (2000). Emissions Scenarios Summary for Policymakers: Intergovernmental Panel on Climate Change.

IPCC. (2013). Climate Change 2013 Summary for Policymakers (Vol. WG I): Intergovernmental Panel of Climate Change.

Joshi, N. P., maharjan, K. L., \& Piya, L. (2011). Effect of Climate Variables on Yield of Major Food-crops in Nepal. Journal of Contemporary India Studies: Space and Society, Hiroshima University, 1, 19-26.

Keeney, R., \& Hertel, T. (2009). The Indirect Land Use Impacts of United States Biofuel Policies: The Importance of Acreage, Yield, and Bilateral Trade Responses. American Journal of Agricultural Economics, 91(4), 895-909. doi: http://dx.doi.org/10.1111/j.1467-8276.2009.01308.x

Knox, J. W., Hess, T. M., Daccache, A., \& Perez Ortola, M. (2011). What are the projected impacts of climate change on food crop productivity in Africa and South Asia? DFID Systematic Review, Final Report (pp. 77 pp.). Cranfield, UK: Cranfield University.

Kumar, K. S. K. (2011). Climate sensitivity of Indian agriculture: do spatial effects matter? Cambridge Journal of Regions, Economy and Society, 4(2), 221-235. doi: http://dx.doi.org/10.1093/cires/rsr004 
Kumar, K. S. K., \& Parikh, J. (2001). Indian agriculture and climate sensitivity. Global Environmental Change, 11(2), 147-154. doi: http://dx.doi.org/10.1016/S0959-3780(01)00004-8

Li, L., Taheripour, F., Preckel, P., \& Tyner, W. E. (2012). Improvement of GTAP Cropland Constant Elasticity of Transformation Nesting Structure. Paper presented at the Agricultural and Applied Economics Association's 2012 AAEA Annual Meeting, Seattle, Washington.

Malla, G. (2008). Climate Change and its Impact on Nepalese Agriculture. The Journal of Agriculture and Environment, 9, 62-71.

Mendelsohn, R. (2007). Measuring Climate Impacts With Cross-Sectional Analysis. Climatic Change, 81(1), 1-7. doi: http://dx.doi.org/10.1007/s10584-005-9007-0

Müller, C., \& Robertson, R. D. (2014). Projecting future crop productivity for global economic modeling. Agricultural Economics, 45(1), 37-50. doi: http://dx.doi.org/10.1111/agec.12088

Nelson, G. C., \& Shively, G. E. (2014). Modeling climate change and agriculture: an introduction to the special issue. Agricultural Economics, 45(1), 1-2. doi: http://dx.doi.org/10.1111/agec.12093

Palatnik, R. R., Kan, I., Rapaport-Rom, M., Ghermandi, A., Eboli, F., \& Shechter, M. (2011). Land transformation analysis and application. Paper presented at the Annual Conference on Global Economic Analysis, Venice, Italy.

Pokhrel, D. M., \& Thapa, G. B. (2007). Are marketing intermediaries exploiting mountain farmers in Nepal? A study based on market price, marketing margin and income distribution analyses. Agricultural Systems, 94(2), 151-164. doi: http://dx.doi.org/10.1016/j.agsy.2006.08.004

Powell, A. A., \& Gruen, F. H. G. (1968). The Constant Elasticity of Transformation Production Frontier and Linear Supply System. International Economic Review, 9(3), 315-328. doi: 10.2307/2556228

Robinson, S., van Meijl, H., Willenbockel, D., Valin, H., Fujimori, S., Masui, T., . . . von Lampe, M. (2014). Comparing supply-side specifications in models of global agriculture and the food system. Agricultural Economics, 45(1), 21-35. doi: http://dx.doi.org/10.1111/agec.12087

Saito, N. (2012). Mainstreaming climate change adaptation in least developed countries in South and Southeast Asia. Mitigation and Adaptation Strategies for Global Change, 18(6), 825-849. doi: http://dx.doi.org/10.1007/s11027-012-9392-4

Salami, H., Shahnooshi, N., \& Thomson, K. J. (2009). The economic impacts of drought on the economy of Iran: An integration of linear programming and macroeconometric modelling approaches. Ecological Economics, 68(4), 1032-1039. doi: http://dx.doi.org/10.1016/i.ecolecon.2008.12.003

Scrieciu, S. S. (2007). The inherent dangers of using computable general equilibrium models as a single integrated modelling framework for sustainability impact assessment. A critical note on Böhringer and Löschel (2006). Ecological Economics, 60(4), 678-684. doi: http://dx.doi.org/10.1016/i.ecolecon.2006.09.012

Seo, S. N., Mendelsohn, R., Dinar, A., Hassan, R., \& Kurukulasuriya, P. (2009). A Ricardian Analysis of the Distribution of Climate Change Impacts on Agriculture across Agro-Ecological Zones in Africa. Environmental and Resource Economics, 43(3), 313-332. doi: http://dx.doi.org/10.1007/s10640-009$\underline{9270-z}$

Thapa, S., \& Joshi, G. R. (2011). A Ricardian analysis of the climate change impact on Nepalese agriculture: Munich Personal RePEc Archive.

UNFCCC. (2015). Adoption of the Paris agreement. Paris, France: United Nations Framework Convention on Climate Change.

World Bank. (2012). Turn Down the Heat: Why a $4^{\circ} \mathrm{C}$ Warmer World Must Be Avoided. Washington D.C.: World Bank. 